\title{
Assessment of Cardiovascular Disease Risk and Therapeutic Patterns among Urban Black Rheumatoid Arthritis Patients
}

\author{
Isabel M. McFarlane ${ }^{1, *}$, Su Yien Zhaz Leon ${ }^{2}$, Manjeet S. Bhamra ${ }^{1}$, Aaliya Burza ${ }^{3}$, \\ Stephen Anthony Waite ${ }^{4}$, Milena Rodriguez Alvarez ${ }^{1}$, Kristaq Koci ${ }^{1}$, Nicholas Taklalsingh ${ }^{1}$, \\ Ian Kaplan ${ }^{1}$, Joshy Pathiparampil ${ }^{1}$, Naureen Kabani ${ }^{1}$, Elsie Watler ${ }^{1}$, Cristina S. Sorrento ${ }^{1}$, \\ Mosab Frefer ${ }^{1}$, Vytas Vaitkus ${ }^{1}$, Jason Green ${ }^{1}$, Keron Matthew ${ }^{1}$, Fray Arroyo-Mercado ${ }^{1}$, \\ Helen Lyo ${ }^{1}$, Faisal Soliman ${ }^{5}$, Randolph A. Sanchez ${ }^{6}$, Felix M. Reyes ${ }^{7}$, David J. Ozeri ${ }^{8}$, \\ Veena Dronamraju ${ }^{1}$, Michael Trevisonno ${ }^{1}$, Christon Grant ${ }^{1}$, Guerrier Clerger ${ }^{1}$, \\ Khabbab Amin ${ }^{1}$ (D), Latoya Freeman ${ }^{1}$, Makeda Dawkins ${ }^{1}$, Diana Lenis Lopez ${ }^{1}$, \\ Jonathan Smerling ${ }^{1}$, Irfan Gondal ${ }^{1}$, Elaine Dellinger ${ }^{1}$, Karen Paltoo ${ }^{1}$, Hina Bhat ${ }^{1}$ and \\ Srinivas Kolla ${ }^{4}$
}

1 Department of Medicine, Division of Rheumatology SUNY Downstate Medical Center/Health + Hospitals Kings County, Brooklyn, NY 11201, USA; Manjeet.Bhamra@downstate.edu (M.S.B.); milena.rodriguezalvarez@downstate.edu (M.R.A.); Kristaq.Koci@downstate.edu (K.K.); Nicholas.Taklalsingh@downstate.edu (N.T.); Ian.Kaplan@downstate.edu (I.K.); Joshy.Pathiparampil@downstate.edu (J.P.); Naureen.Kabani@downstate.edu (N.K.); Elsie.Watler@nychhc.org (E.W.); Cristina.Sorrento@downstate.edu (C.S.S.); Mosab.Frefer@downstate.edu (M.F.); Vytas.Vaitkus@downstate.edu (V.V.); Jason.Green@downstate.edu (J.G.); Keron.Matthew@downstate.edu (K.M.); Fray.Arroyo-Mercado@downstate.edu (F.A.-M.); Helen.Lyo@downstate.edu (H.L.); veena.dronamraju@downstate.edu (V.D.); Michael.Trevisonno@downstate.edu (M.T.); Christon.Grant@downstate.edu (C.G.); Guerrier.Clerger@downstate.edu (G.C.); khabbab.amin@downstate.edu (K.A.); Latoya.Freeman@downstate.edu (L.F.); Makeda.Dawkins@downstate.edu (M.D.); Diana.Lenis@downstate.edu (D.L.L.); Jonathan.Smerling@downstate.edu (J.S.); Irfan.Gondal@downstate.edu (I.G.); Elaine.Dellinger@downstate.edu (E.D.); Karen.Paltoo@downstate.edu (K.P.); Hina.Bhat@downstate.edu (H.B.)

2 Samaritan Medical Center Department of Rheumatology, Watertown, NY 13601, USA; szhaz@shsny.com

3 Department of Medicine, Division of Pulmonary and Critical Care State, SUNY Downstate Medical Center/Health + Hospitals Kings County, Brooklyn, NY 11201, USA; Aaliya.Burza@downstate.edu

4 Department of Radiology SUNY Downstate Medical Center/Health + Hospitals Kings County, Brooklyn, NY 11201, USA; Stephen.Waite@downstate.edu (S.A.W.); Srinivas.Kolla@downstate.edu (S.K.)

5 Department of Geriatrics, New York Presbyterian Brooklyn Methodist Hospital, Brooklyn, NY 11201, USA; fas9051@nyp.org

6 Department of Rheumatology, Hahnemann Hospital, Philadelphia, PA 19019, USA; Randysanchez2011@gmail.com

7 Department of Family and Social Medicine, Montefiore Medical Center Albert Einstein College of Medicine, Bronx, NY 10468, USA; freyesv@montefiore.org

8 Sheba Medical Center, Tel Aviv 6100000, Israel; david.ozeri@sheba.health.gov.il

* Correspondence: Isabel.McFarlane@downstate.edu; Tel.: +718-270-2390

Received: 26 December 2018; Accepted: 27 January 2019; Published: 20 February 2019

Abstract: Rheumatoid arthritis (RA) patients have nearly twice the risk of cardiovascular disease (CVD) compared to the general population. We aimed to assess, in a predominantly Black population, the prevalence of traditional and RA-specific CVD risk factors and therapeutic patterns. Utilizing ICD codes, we identified 503 RA patients $\geq 18$ years old who were seen from 2010 to 2017. Of them, $88.5 \%$ were Black, $87.9 \%$ were women and $29.4 \%$ were smokers. CVD risk factors (obesity, diabetes, 
hypertension, dyslipidemia) were higher than in previously reported White RA cohorts. Eighty-seven percent of the patients had at least one traditional CVD risk factor, $37 \%$ had three or more traditional CVD risk factors and $58 \%$ had RA-specific risk factors (seropositive RA, $>10$ years of disease, joint erosions, elevated inflammatory markers, extra-articular disease, body mass index $(\mathrm{BMI})<20)$. CV outcomes (coronary artery disease/myocardial infarction, heart failure, atrial fibrillation and stroke) were comparable to published reports. Higher steroid use, which increases CVD risk, and lesser utilization of biologics (decrease CV risk) were also observed. Our Black RA cohort had higher rates of traditional CVD risk factors, in addition to chronic inflammation from aggressive RA, which places our patients at a higher risk for CVD outcomes, calling for revised risk stratification strategies and effective interventions to address comorbidities in this vulnerable population.

Keywords: rheumatoid arthritis; traditional risk factors; rheumatoid arthritis specific risk factors; seropositive rheumatoid arthritis; erosive disease; extra-articular manifestations; cardiovascular outcomes; therapeutic patterns

\section{Introduction}

Rheumatoid arthritis (RA) is a chronic inflammatory condition that affects about $1 \%$ of the adult population, with an annual incidence rate of 40 new cases per 100,000 persons [1,2]. The pathophysiology of RA involves a complex interplay of environmental and genetic factors, leading to chronic inflammation that erodes articular cartilage and bone. Thus, RA presents with joint pain, swelling and stiffness as inflammation and synovitis develops [1]. Chronic inflammation can impact other organ systems, leading to extra-articular manifestations including rheumatoid nodules, vasculitis, interstitial lung disease and premature death [3]. About half of all RA-related deaths can be attributed to CVD, as inflammation has been shown to play a key role at every stage of atherogenesis, further strengthening the association between cardiovascular disease (CVD) and RA [3-7]. The degree of CVD involvement in RA has been shown to correlate with the degree of systemic inflammation [8-10]. In support of this association, disease-modifying, anti-rheumatic drugs (DMARDs) and biologics in RA have been shown to confer protection from CVD-related events [11-14]. Recently, epidemiologic data indicates that African American patients have higher rates of CVD associated with connective tissue disease compared with white patients [15]. In this study, we aimed to assess the prevalence of CVD risk factors and outcomes in a predominantly Black RA population.

\section{Methods}

In this cross-sectional study, we utilized the International Classification of Diseases, Ninth Revision, Clinical Modification (ICD-9-CM 714.0) and the International Classification of Diseases, Tenth Revision (ICD-10-CM M06.00-M06.09), to identify RA as either the principal or secondary diagnosis in the discharge summary. We included all inpatient discharges, from 1 January 2010 to 30 May 2017, that took place at State University of New York Downstate Medical Center-University Hospital of Brooklyn and New York City (NYC) Health + Hospitals/Kings County, which serve the population of Central Brooklyn, NY. Prior to the initiation of the study, the protocol was approved by the SUNY Downstate Institutional Review Board and the Office of Research Administration for implementation at NYC Health + Hospitals/Kings County. We selected patients, 18 years or older by 1 January 2010 to be included in the study. Two investigators (IMM, SYZ) independently reviewed the cases identified by ICD-codes to confirm RA diagnosis. We used physician entries (inpatient/outpatient notes and consultations) and the presence of disease-modifying anti-rheumatic drugs (DMARDs) in the medication reconciliation or DMARDs prescriptions. Data abstraction was performed for confirmed cases utilizing the study data collection sheet. Demographics and clinical data including history 
of smoking, year of RA-diagnosis (according to 2010 American College of Rheumatology criteria), comorbidities, laboratory data, hand imaging and treatment regimens were abstracted [15].

A musculoskeletal radiologist (SK) evaluated the bilateral hand radiographs utilizing the Simple Erosion Narrowing Score (SENS) to ascertain the presence and number of erosions and joint space narrowing [16]. The radiologist was blinded to the serologic status of the reviewed cases.

Descriptive statistics using IBM ${ }^{\circledR}$ SPSS version 23 (name, city, state, country) was applied. Measures of central tendency and dispersion for continuous variables, and frequency distribution for categorical variables were used. Data is presented as the mean \pm standard error of the mean $( \pm \mathrm{SEM})$. We compared our predominantly Black RA population with the predominantly White cohort of the Consortium of Rheumatology Researchers of North America (CORRONA) to assess differences in CVD risk profiles, CVD outcomes, features of RA disease severity, and therapeutic patterns including the use of steroids, DMARDs and biologics [7]. We used a $t$-test to compare between groups for continuous variables, and Chi square analysis for categorical ones.

\section{Results}

Of the 1142 RA patients identified by ICD codes, 281 had no clinical documentation to support RA diagnosis, 88 had insufficient data for confirmation of RA diagnosis, and 248 had an alternative diagnosis. Forty-four records were identified as duplicates and abstracted as 22 unique patients. This process resulted in the identification of 503 patients with confirmed RA that were included in this analysis (Figure 1). The mean disease duration (in years) was $13.1 \pm 0.7$, and mean patients' age was $64.7 \pm 0.6( \pm \mathrm{SEM})$. Of them, $87.9 \%$ were women, $88.5 \%$ were Black and $9.2 \%$ Hispanics. Mean body mass index (BMI) was $28.92 \pm 0.36$ with $37.2 \%$ of the patients having a BMI $\geq 30\left(\mathrm{Kg} / \mathrm{m}^{2}\right)$. Women were significantly older compared to men, with a mean age of $65 \pm 0.67 \mathrm{vs} .61 \pm 2.19$ respectively $(p<0.04)$ (Table 1$)$.

Table 1. Population characteristics.

\begin{tabular}{|c|c|}
\hline \multicolumn{2}{|c|}{$\begin{array}{l}\text { Total Number of Patients: } 503 \\
\text { Mean Age } 64.76 \pm 0.66( \pm \text { SEM })\end{array}$} \\
\hline Number of women & $87.9 \%$ \\
\hline Number of men & $12.1 \%$ \\
\hline Women's mean age $( \pm S E M)$ years & $65 \pm 0.68$ \\
\hline All patients age in years $( \pm$ SEM $)$ & $64.7 \pm 0.6$ \\
\hline \multicolumn{2}{|c|}{ Race/Ethnicity } \\
\hline White & $7.2 \%$ \\
\hline Black & $88.5 \%$ \\
\hline Native American & $0.2 \%$ \\
\hline Asian Pacific Islander & $0.6 \%$ \\
\hline Hispanics & $9.2 \%$ \\
\hline \multicolumn{2}{|c|}{ Other Characteristics } \\
\hline Non-smoker & $70.6 \%$ \\
\hline Ever smoker & $29.4 \%$ \\
\hline $\mathrm{BMI}($ mean \pm SEM) & $28.9 \pm 0.36$ \\
\hline $\mathrm{BMI} \geq 30 \mathrm{Kg} / \mathrm{m}^{2}$ & $37.2 \%$ \\
\hline Diabetes mellitus & $28.5 \%$ \\
\hline Hypertension & $66.6 \%$ \\
\hline Hyperlipidemia & $41.3 \%$ \\
\hline CAD or AMI & $19.8 \%$ \\
\hline Prior cerebrovascular accident & $10.1 \%$ \\
\hline Atrial fibrillation & $8.4 \%$ \\
\hline Congestive heart failure & $14.8 \%$ \\
\hline
\end{tabular}

Percentages were calculated based on the number of patients with data available on the measure. CAD: coronary artery disease; MI: myocardial infarction, BMI: body mass index, SEM: standard error of the mean. 
The rates of traditional CVD risk factors in our study cohort (predominantly Black) vs. the CORRONA study cohort (predominantly White) respectively were: hypertension (66.6\% vs. $29 \%$ ), dyslipidemia ( $41.3 \%$ vs. $25 \%$ ), diabetes ( $28.5 \%$ vs. $8 \%$ ), and smoking $(29.4 \%$ vs. $34 \%$ ) (Table 1$)$.

CVD risk factors were not significantly different between men and women in our cohort (Table 2). At least one traditional CVD risk factor (BMI $\geq 30$, positive smoking history, dyslipidemia, diabetes or hypertension) was encountered in $87.4 \%$ of the RA cohort with the presence of three or more traditional risk factors occurring in 37\%. Rheumatoid arthritis-specific risk factors (RA disease more than 10 years, presence of joint erosions, joint space narrowing, extra-articular manifestations, $\mathrm{BMI}<20$, Rheumatoid Factor (RF) or anti-citrullinated peptide antibodies (ACPA) positivity, erythrocyte sedimentation rate $(E S R) \geq 42 \mathrm{~mm} / \mathrm{h}$. or C-reactive protein $(\mathrm{CRP}) \geq 10 \mathrm{mg} / \mathrm{L}$ ) were seen in $58 \%$ of the cases (Table 3 ).
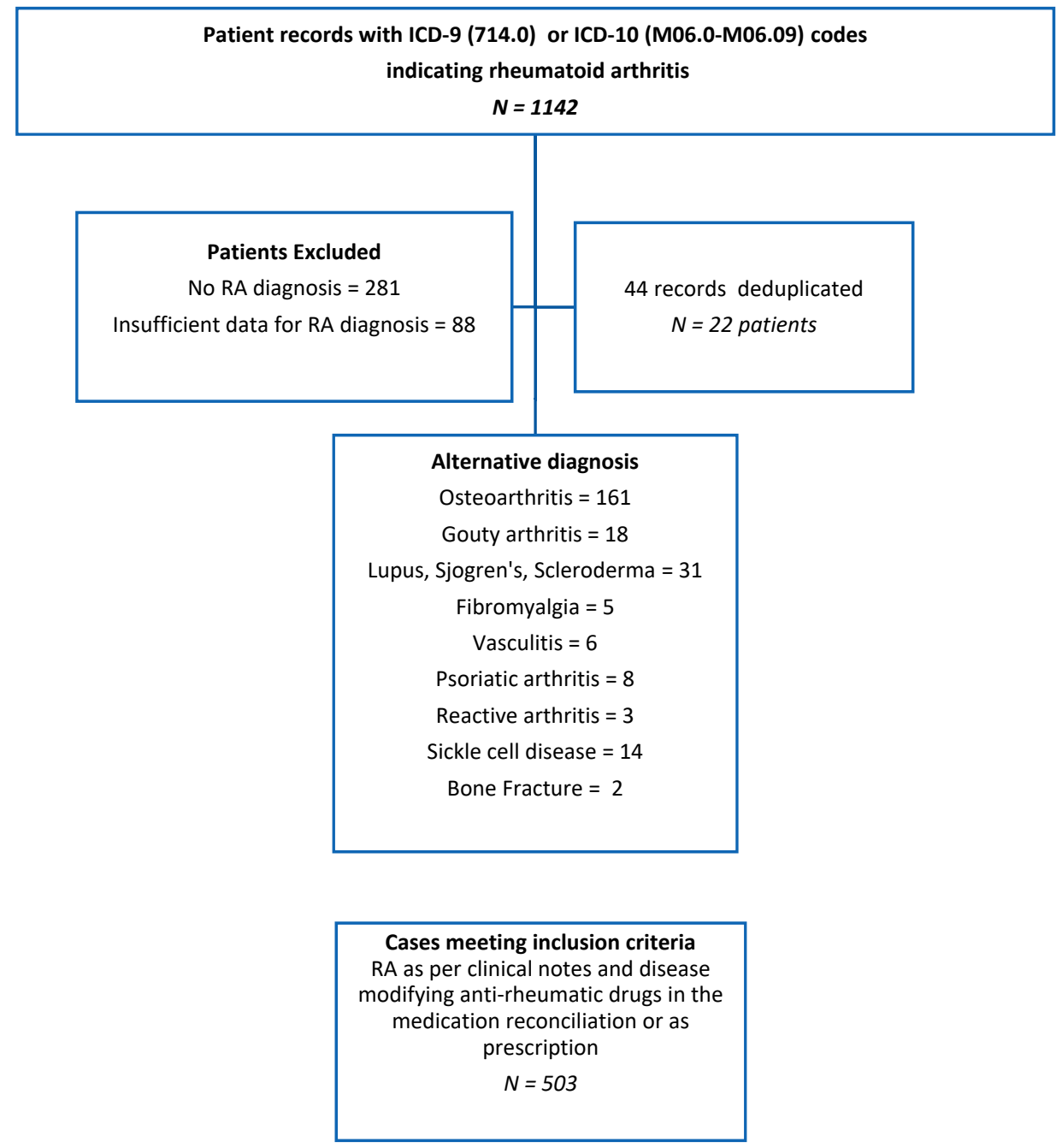

Figure 1. Flow chart delineating the selection procedure of the rheumatoid arthritis cases in the study.ICD-9: International Classification of Diseases, Ninth Revision, Clinical Modification, ICD-10: International Classification of Diseases, Tenth Revision, Clinical Modification.

The examined CVD outcomes included myocardial infarction (MI) or known coronary artery disease (CAD) (19.8\%), which were similar to those reported in the CORRONA study [7]. The rates of other CVDs in our cohort that were not reported in the CORRONA study were: congestive heart failure (14.8\%), stroke or transient ischemic attack (10.1\%) and atrial fibrillation (8.4\%). For ESR, the mean was $62.7 \pm 2.1 \mathrm{~mm} / \mathrm{h}$., CRP was $48.7 \pm 4.2$ and CRP $>4 \mathrm{mg} / \mathrm{L}$ was found in $74.6 \%$ of our cohort. $86.6 \%$ of our patients were either RF or ACPA positive (compared to $77 \%$ in the CORRONA study), and dual RF-ACPA positivity was found in $54 \%$. We also compared the rates of traditional CVD risk 
factors, CV outcomes and RA-specific risk factors among the seropositive and seronegative groups; statistical significance was found for the frequency of RA-specific risk factors ( $89.5 \% \mathrm{vs.} 67.7 \%)$ and ESR $\geq 42 \mathrm{~mm} / \mathrm{h}$. (70\% vs. $38.4 \%) p<0.001$ (Table 3 ).

Table 2. Gender comparison.

\begin{tabular}{ccc}
\hline & $\begin{array}{c}\text { Women } \\
(\boldsymbol{n}=\mathbf{4 4 2})\end{array}$ & $\begin{array}{c}\text { Men } \\
(\boldsymbol{n}=\mathbf{6 1})\end{array}$ \\
\hline Age in years (mean \pm SEM) & $65.2 \pm 0.6$ & $61 \pm 2.1$ \\
Ever smoker (current/past) & $(28.2 \%)$ & $(37.9 \%)$ \\
BMI Kg $/ \mathrm{m}^{2}($ mean \pm SEM) & $29.9 \pm 0.382$ & $12 / 50(24 \%)$ \\
BMI $>30 \mathrm{Kg} / \mathrm{m}^{2}$ & $157 / 404(38.9 \%)$ & $15 / 58(25.9 \%)$ \\
Diabetes mellitus & $121 / 419(28.9 \%$ & $36 / 59(61 \%)$ \\
Hypertension & $289 / 429(67.4 \%)$ & $20 / 59(33.9 \%)$ \\
Hyperlipidemia & $172 / 406(42.4 \%)$ & $11 / 55(20 \%)$ \\
CAD or MI & $77 / 390(19.7 \%)$ & $4 / 57(7 \%)$ \\
Prior cerebrovascular accident & $42 / 398(10.6 \%)$ & $4 / 56(7.1 \%)$ \\
Atrial fibrillation & $35 / 409(8.6 \%)$ & $5 / 57(8.8 \%)$ \\
Congestive heart failure & $65 / 417(15.6 \%)$ &
\end{tabular}

Percentages were calculated based on the number of patients with data available on the measure.

Table 3. Cardiovascular risk factors and outcomes considering the serotype.

\begin{tabular}{|c|c|c|c|c|}
\hline & All Patients & $\begin{array}{l}\text { Seropositive RF+ } \\
\text { and/or ACPA+ } \\
(n=201)\end{array}$ & $\begin{array}{l}\text { Seronegative RF- } \\
\text { and ACPA- } \\
(n=31)\end{array}$ & $p$-Value \\
\hline \multicolumn{5}{|l|}{ Cardiovascular risk factors } \\
\hline Hypertension (HTN) & $325 / 488(66.6 \%)$ & $65 / 129(50.4 \%)$ & $20 / 30(66.6 \%)$ & 0.98 \\
\hline Hyperlipidemia (HLP) & $192 / 465(41.3 \%)$ & $77 / 185(41.6 \%)$ & $15 / 31(48.4 \%)$ & 0.48 \\
\hline Diabetes mellitus (DM) & $136 / 477(28.5 \%)$ & $28 / 175(16 \%)$ & $4 / 29(13.7 \%)$ & 0.76 \\
\hline \multicolumn{5}{|l|}{ Traditional risk factors for CVD } \\
\hline Any traditional CVD risk factor present & $436 / 499(87.4 \%)$ & $175 / 199(87.9 \%)$ & $29 / 31(93.5 \%)$ & 0.35 \\
\hline$\geq 3$ traditional risk factors & $157 / 425(37 \%)$ & $67 / 194(34.5 \%)$ & $7 / 29(24.3 \%)$ & 0.27 \\
\hline \multicolumn{5}{|l|}{$\begin{array}{l}\text { Rheumatoid arthritis-specific risk } \\
\text { factors }\end{array}$} \\
\hline RA-specific risk factors for CVD & $292 / 503(58 \%)$ & $180 / 201(89.5 \%)$ & $21 / 31(67.7)$ & $0.001 *$ \\
\hline RA duration of disease $>10$ years & $108 / 197(54.8 \%)$ & $61 / 114(53.5 \%)$ & $11 / 16(68.5 \%)$ & 0.25 \\
\hline $\mathrm{BMI}<20 \mathrm{Kg} / \mathrm{m}^{2}$ & $34 / 454(7.5 \%)$ & $16 / 189(8.4 \%)$ & $1 / 27(3.7 \%)$ & 0.39 \\
\hline Joint erosions & $125 / 188(66.5 \%)$ & $82 / 120(68.3 \%)$ & $6 / 13(46.15 \%)$ & 0.11 \\
\hline Joint space narrowing & $130 / 188(69.1 \%)$ & $84 / 120(70 \%)$ & $7 / 13(53.8 \%)$ & 0.23 \\
\hline Extra-articular disease & $38 / 503(7.5 \%)$ & $12 / 201(6.9 \%)$ & $0 / 31(0 \%)$ & 0.13 \\
\hline $\mathrm{CRP}>10 \mathrm{mg} / \mathrm{L}^{* *}$ & $180 / 285(63.1 \%)$ & $102 / 171(56.9 \%)$ & $12 / 24(50 \%)$ & 0.36 \\
\hline $\mathrm{ESR}>42 \mathrm{~mm} / \mathrm{h}^{* * *}$ & $198 / 313(63.1 \%)$ & $124 / 177(70 \%)$ & $10 / 26(38.4 \%)$ & $0.001^{*}$ \\
\hline Positive Rheumatoid Factor (RF) & $186 / 247(75.3 \%)$ & $186 / 247(75.3 \%)$ & $0 \%$ & NA \\
\hline Positive Anti-citrullinated ab. (ACPA) & $124 / 178(69.6 \%)$ & $124 / 178(69.6 \%)$ & $0 \%$ & NA \\
\hline Either RF+ or ACPA+ & $201 / 232(86.6 \%)$ & $201 / 232(86.6 \%)$ & $0 \%$ & NA \\
\hline Double seropositive $(\mathrm{RF}+$ and $\mathrm{ACPA}+)$ & $109 / 201(54 \%)$ & $109 / 201(54 \%)$ & $0 \%$ & NA \\
\hline \multicolumn{5}{|l|}{ Cardiovascular outcomes } \\
\hline Congestive heart failure & $70 / 474(14.8 \%)$ & $27 / 188(14.3 \%)$ & $2 / 30(6.6 \%)$ & 0.25 \\
\hline CAD or MI & $88 / 445(19.8 \%)$ & $28 / 175(16 \%)$ & $4 / 29(13.8 \%)$ & 0.76 \\
\hline Prior cerebrovascular accident (CVA) & $46 / 455(10.1 \%)$ & $18 / 183(9.8 \%)$ & $3 / 29(10.3 \%)$ & 0.93 \\
\hline Atrial fibrillation & $39 / 465(8.4 \%)$ & $14 / 187(7.4 \%)$ & $1 / 30(3.3 \%)$ & 0.41 \\
\hline Any CVD outcome & $175 / 503(34.8 \%)$ & $59 / 201(29.4 \%)$ & $10 / 31(32.3 \%)$ & 0.29 \\
\hline
\end{tabular}

Utilizing SENS scoring for hand radiographs, periarticular osteopenia, joint space narrowing and joint erosions were observed in $95.2 \%, 69 \%$ and $66.5 \%$ respectively of our RA patients, while joint erosions were reported in 50.7\% of the cohort in the 2010 CORRONA study [19]. Our patients' mean number of joint erosions was $10.73 \pm 0.98$ (maximum $=32$ ) and the mean number of joint space narrowing was $17 \pm 1.05$ (maximum $=30$ ). No statistical significance was noted among the 
seropositive and seronegative groups for hand imaging findings. We recorded glucocorticoid use in $56 \%$ of our patients (vs. 30\% for CORRONA) with an average dose of $8.1 \pm 0.95 \mathrm{mg} /$ day, nonsteroidal anti-inflammatory drugs (NSAIDs) use in $22 \%$ and narcotics in $8.1 \%$. With regard to DMARDs use, $40.3 \%$ of the patients were on Methotrexate with an average dose of $6.6 \pm 0.47 \mathrm{mg}$ /week, other DMARDs in $43 \%$ and biologics in $16.2 \%$ (Table 4 ). Our data also demonstrates a higher CV burden and higher CV outcomes among steroid users in contrast with the lower rates of CV outcomes in non-steroid users treated with DMARDs and biologics (Table 5).

Table 4. Therapeutic Management.

\begin{tabular}{lc}
\hline \multicolumn{1}{c}{ Glucocorticoids } & $\mathbf{2 3 8 / 4 2 5}(\mathbf{5 6} \%)$ \\
\hline PDN mean daily dose $( \pm$ SEM) in mg. & $8.14 \pm 0.95$ \\
NSAIDs & $89 / 406(22.1 \%)$ \\
Narcotics & $33 / 406(8.1 \%)$ \\
Methotrexate (MTX) & $175 / 434(40.3 \%)$ \\
MTX mean weekly dose ( \pm SEM) in mg. & $6.6 \pm 0.47$ \\
Other DMARDs & $153 / 356(43 \%)$ \\
Biologics & $68 / 420(16.2 \%)$ \\
\hline
\end{tabular}

PDN: Prednisone, NSAID: nonsteroidal anti-inflammatory drugs, DMARD: disease-modifying, anti-rheumatic drugs.

Table 5. Therapeutic regimens and associated CVD risk factors and outcomes.

\begin{tabular}{cccc}
\hline & Only Steroids & $\begin{array}{c}\text { Steroids and } \\
\text { DMARDs/Biologics }\end{array}$ & $\begin{array}{c}\text { Only } \\
\text { DMARDs/Biologics }\end{array}$ \\
\hline Any CVD risk factor & $205 / 436(47 \%)$ & $152 / 436(34.9 \%)$ & $119 / 436(27.3 \%)$ \\
$\geq 3$ CVD risk factors & $69 / 157(44 \%)$ & $52 / 157(33.1 \%)$ & $46 / 157(29.3 \%)$ \\
Any CVD outcome & $81 / 175(46.3 \%)$ & $62 / 175(35.4 \%)$ & $45 / 175(25.7 \%)$ \\
\hline
\end{tabular}

\section{Discussion}

Our predominantly Black RA population had higher rates of CVD risk factors compared to predominantly White RA cohorts of previous studies. These CVD risk factors included obesity, hypertension, dyslipidemia and diabetes. The CORRONA is a US-based registry of about 25,000 RA patients which is followed longitudinally [7]. RA disease activity and its impact on cardiovascular (CV) end points have been the subject of a number of publications by the CORRONA investigators $[6,7,19,20]$. Eighty-nine percent of the patients in the CORRONA registry are White, contrasting with our inner-city RA population of $88.5 \%$ Black and $9.2 \%$, Hispanics.

Similarities between our study cohort and the CORRONA cohort include female predominance and nearly identical BMI (28.9 vs. 29.2). However, our population differs from the CORRONA patients in a number of characteristics. Lower rates of current smokers and ever smokers were found among our patients, i.e., $11.5 \%$ and $29.5 \%$ respectively (vs. $19 \%$ and $37 \%$ in CORRONA respectively), and higher rates of hypertension, dyslipidemia and diabetes. Eighty-seven percent of our patients have at least one traditional CVD risk factor present, with more than a third of them carrying three or more traditional risk factors, which supports the notion that our population is at a higher risk for CVD events and mortality.

Our RA population was also found to have a higher frequency of seropositivity, as demonstrated by the presence of rheumatoid factor or anti-citrullinated antibodies ( $85.8 \% \mathrm{vs} .77 \%$ in CORRONA), and more than half of our patients had had RA disease for longer than 10 years. Our study includes radiological evaluation with evidence of joint damage (e.g., joint erosions and joint space narrowing) as markers of disease severity. Furthermore, our study examined the presence of extra-articular manifestations of RA (e.g., vasculitis, ocular involvement, subcutaneous nodules and interstitial lung disease), and recorded $7.5 \%$ of patients with a BMI $<20$ (rheumatoid cachexia). The aggressive nature of RA disease seen in our cohort is further supported by the frequency of elevated inflammatory markers 
such as CRP and ESR. We also found a statistically-significant difference between the seropositive and seronegative RA groups in the rates of RA-specific CVD risk factors, with seropositive patients exhibiting higher prevalence of joint erosions, joint space narrowing, extra-articular disease and elevated serum markers. Seronegative patients demonstrated higher rates of hypertension compared with the seropositive group ( $66.6 \%$ vs. $50.4 \%$ respectively); however, this finding was not statistically significant, likely due to the small sample size. Furthermore, our data demonstrates a higher burden of both traditional and RA-specific risk factors in our study cohort as compared with the CORRONA cohort [7]. Interestingly, the rate of CAD was similar (19.8\%) to the one observed in the 2015 CORRONA study $(17 \%)$, although a higher rate of CAD or MI amongst our patients is to be expected, given the high inflammatory burden. However, earlier data from the CORRONA cohort [19] revealed that only $8.5 \%$ of the patients had CAD at baseline, indicating that our cross-sectional study has captured higher rates of $\mathrm{CAD}$ in our population.

Increased risk for CVD events and mortality in RA has been the subject of several meta-analyses, population studies and mechanistic experiments [4,21,22]). Chronic inflammation contributes to atherosclerosis and CVD. Serum markers have also been found to be independent predictors of CAD and ischemic strokes $[14,17,18]$. Elevated CRP portends higher risk for MI, heart failure, atherosclerosis and mortality among RA patients [23,24]. In addition, high ESR has been associated with CVD risk. ESR $>42 \mathrm{~mm} / \mathrm{h}$. was shown to be linked to MI and stroke, with levels above $50 \mathrm{~mm} / \mathrm{hr}$. increasing 10-fold the risk for CVD [18]. Furthermore, efforts to develop a reliable RA CVD risk score have resulted in overestimates or underestimates of CVD risk in RA population [14].

RA patients are prone to a specific form of dyslipidemia which is characterized by high levels of triglycerides, low levels of both low-density lipoproteins (LDL) and high density lipoproteinemia. This phenomenon is called "lipid paradox" given that there is increased CV risk despite low levels of lipoproteins. High-density lipoprotein appears to be dysfunctional in RA patients, leading to inadequate clearance of lipids from the atheromatous plaque formation. This pro-inflammatory high-density lipoprotein positively correlates with elevated acute phase reactants and disease activity [25-28]. We can postulate that in our population, active RA disease and elevated inflammatory markers contribute to the high prevalence of the observed traditional CVD risk factors.

The obesity rates observed in our population could be explained by decreased physical activity secondary to active RA disease, which further contributes to the burden of traditional CVD risk. On the other hand, "obesity paradox" is also observed in RA, with BMI $<20 \mathrm{Kg} / \mathrm{m}^{2}$ correlating with high disease activity and higher BMI reflecting better disease control [14].

Additionally, the higher use of prednisone among our patients, administered for disease control, adds to the CVD risk [29]. Methotrexate, DMARDs and biologics administered to manage RA have been demonstrated to reduce CV risk among RA patients given their effect on reducing chronic inflammation [14]. In contrast, in our patient population, the utilization rates of methotrexate, DMARDs and biologics were found to be lower than those observed in the CORRONA registry.

Finally, our study is limited by the retrospective nature of the analysis, lack of available RA-specific disease activity measurements, characterization of cardiac involvement, stroke type (ischemic vs. hemorrhagic), response to therapeutic interventions and survival outcomes. Inaccuracy in coding explains the number of cases in which RA diagnosis was not found in the clinical documentation. There is also data missing at random, which we believe is harmless and does not represent a systematic bias. We plan, however, to undertake a longitudinal study to assess disease activity at presentation and at follow-up intervals, disease complications including CVD events, response to primary and secondary prevention of traditional and RA specific risk factors and outcomes. We also acknowledge the limitation of the gender comparison made in Table 2, given the limited number of men in RA, a predominantly female disorder. 


\section{Conclusions}

This is the first study to evaluate CVD risk in a predominately Black RA population that included radiological as well as serological assessment of disease severity, together with characterization of therapeutic patterns. We observed higher rates of traditional CVD risk factors, including obesity, diabetes, hypertension, dyslipidemia, compared to the White RA cohort. Our population had more aggressive disease with higher rates of seropositivity, joint narrowing/erosions and elevated inflammatory markers. The combination of higher rates of traditional and RA-specific risk factors confers on our patients a high risk for CVD events. Our RA population characteristics require therapeutic interventions to address disease control and targeted management of comorbidities that involve revised risk stratification aiming at reducing CVD morbidity and mortality in this highly vulnerable population.

Author Contributions: I.M.M. had full access to all of the data in the study and takes responsibility for the integrity of the data and the accuracy of the data analysis. Conceptualization: I.M.M., D.J.O.; Methodology: I.M.M., S.Y.Z.L., D.J.O.; Validation: I.M.M., S.Y.Z.L., M.S.B., E.W., C.S.S.; Formal analysis: I.M.M., M.S.B., C.S.S., M.R.A.; Investigation: I.M.M., S.Y.Z.L., M.S.B., M.R.A., K.K., N.T., I.K., S.K., S.A.W., A.B., J.P., N.K., E.W., M.F., V.V., J.G., K.M., F.A.-M., H.L., R.A.S., F.S., F.M.R., V.D., M.T., C.G., C.G., K.A., L.F., M.D.; Data curation: I.M.M., S.Y.Z.L., M.S.B.; Writing—original draft: D.L.L., J.S., I.G., E.D., K.P., H.B.; Writing一review and editing: I.M.M., M.S.B., S.Y.Z.L., M.R.A.; Visualization: N.T., M.S.B., M.R.A.; Project administration, S.Y.Z.L., I.M.M., M.S.B.

Funding: This work is supported in part by Dr. Moro O. Salifu's efforts through NIH Grant \# S21MD012474.

Acknowledgments: We are grateful to Chao Ma, Sharlene Mills, Denton Smith and Stuart Clenman for their help with data retrieval and organization.

Conflicts of Interest: The authors declare no conflict of interest.

\section{References}

1. McInnes, I.B.; Schett, G. The pathogenesis of rheumatoid arthritis. N. Engl. J. Med. 2011, 365, $2205-2219$. [CrossRef] [PubMed]

2. Peschken, C.A.; Esdaile, J.M. Rheumatic diseases in North America's indigenous peoples. Semin. Arthritis Rheum. 1999, 28, 368-391. [CrossRef]

3. England, B.R.; Sayles, H.; Michaud, K.; Caplan, L.; Davis, L.A.; Cannon, G.W.; Sauer, B.C.; Solow, E.B.; Reimold, A.M.; Kerr, G.S.; et al. Cause-Specific Mortality in Male US Veterans With Rheumatoid Arthritis. Arthritis Care Res. 2016, 68, 36-45. [CrossRef] [PubMed]

4. Avina-Zubieta, J.A.; Choi, H.K.; Sadatsafavi, M.; Etminan, M.; Esdaile, J.M.; Lacaille, D. Risk of cardiovascular mortality in patients with rheumatoid arthritis: A meta-analysis of observational studies. Arthritis Rheum. 2008, 59, 1690-1697. [CrossRef] [PubMed]

5. Sokka, T.; Abelson, B.; Pincus, T. Mortality in rheumatoid arthritis: 2008 update. Clin. Exp. Rheumatol. 2008, 26 (5 Suppl. 51), S35-S61. [PubMed]

6. Solomon, D.H.; Karlson, E.W.; Rimm, E.B.; Cannuscio, C.C.; Mandl, L.A.; Manson, J.E.; Stampfer, M.J.; Curhan, G.C. Cardiovascular morbidity and mortality in women diagnosed with rheumatoid arthritis. Circulation 2003, 107, 1303-1307. [CrossRef] [PubMed]

7. Solomon, D.H.; Reed, G.W.; Kremer, J.M.; Curtis, J.R.; Farkouh, M.E.; Harrold, L.R.; Hochberg, M.C.; Tsao, P.; Greenberg, J.D. Disease activity in rheumatoid arthritis and the risk of cardiovascular events. Arthritis Rheumatol. 2015, 67, 1449-1455. [CrossRef]

8. Del Rincon, I.; Williams, K.; Stern, M.P.; Freeman, G.L.; O’Leary, D.H.; Escalante, A. Association between carotid atherosclerosis and markers of inflammation in rheumatoid arthritis patients and healthy subjects. Arthritis Rheum. 2003, 48, 1833-1840. [CrossRef]

9. Kurmann, R.D.; Mankad, R. Atherosclerotic Heart Disease in Women With Autoimmune Rheumatologic Inflammatory Conditions. Can. J. Cardiol. 2018, 34, 381-389. [CrossRef]

10. Sanjadi, M.; Rezvanie Sichanie, Z.; Totonchi, H.; Karami, J.; Rezaei, R.; Aslani, S. Atherosclerosis and autoimmunity: A growing relationship. Int. J. Rheum. Dis. 2018, 21, 908-921. [CrossRef] 
11. Fava, C.; Montagnana, M. Atherosclerosis Is an Inflammatory Disease which Lacks a Common Anti-inflammatory Therapy: How Human Genetics Can Help to This Issue A Narrative Review. Front. Pharmacol. 2018, 9, 55. [CrossRef] [PubMed]

12. Herrinton, L.J.; Ray, G.T.; Curtis, J.R.; Wu, J.J.; Fireman, B.; Liu, L.; Goldfien, R. An Observational Study of Cardiovascular Risks Associated with Rheumatoid Arthritis Therapies: A Comparison of Two Analytical Approaches. Perm. J. 2018, 22. [CrossRef]

13. Mangoni, A.A.; Zinellu, A.; Sotgia, S.; Carru, C.; Piga, M.; Erre, G.L. Protective Effects of Methotrexate against Proatherosclerotic Cytokines: A Review of the Evidence. Mediat. Inflamm. 2017, 2017, 9632846. [CrossRef] [PubMed]

14. Urman, A.; Taklalsingh, N.; Sorrento, C.; McFarlane, I.M. Inflammation Beyond the Joints: Rheumatoid Arthritis and Cardiovascular Disease. SciFed J. Cardiol. 2018, 2, 1-23.

15. Aletaha, D.; Neogi, T.; Silman, A.J.; Funovits, J.; Felson, D.T.; Bingham, C.O., 3rd; Birnbaum, N.S.; Burmester, G.R.; Bykerk, V.P.; Cohen, M.D.; et al. 2010 rheumatoid arthritis classification criteria: An American College of Rheumatology/European League Against Rheumatism collaborative initiative. Ann. Rheum. Dis. 2010, 69, 1580-1588. [CrossRef] [PubMed]

16. Dias, E.M.; Lukas, C.; Landewe, R.; Fatenejad, S.; van der Heijde, D. Reliability and sensitivity to change of the Simple Erosion Narrowing Score compared with the Sharp-van der Heijde method for scoring radiographs in rheumatoid arthritis. Ann. Rheum. Dis. 2008, 67, 375-379. [CrossRef] [PubMed]

17. Zhang, J.; Chen, L.; Delzell, E.; Muntner, P.; Hillegass, W.B.; Safford, M.M.; Millan, I.Y.; Crowson, C.S.; Curtis, J.R. Republished: The association between inflammatory markers, serum lipids and the risk of cardiovascular events in patients with rheumatoid arthritis. Postgrad. Med. J. 2014, 90, 722-729. [CrossRef] [PubMed]

18. Myasoedova, E.; Crowson, C.S.; Kremers, H.M.; Roger, V.L.; Fitz-Gibbon, P.D.; Therneau, T.M.; Gabriel, S.E. Lipid paradox in rheumatoid arthritis: The impact of serum lipid measures and systemic inflammation on the risk of cardiovascular disease. Ann. Rheum. Dis. 2011, 70, 482-487. [CrossRef] [PubMed]

19. Solomon, D.H.; Kremer, J.; Curtis, J.R.; Hochberg, M.C.; Reed, G.; Tsao, P.; Farkouh, M.E.; Setoguchi, S.; Greenberg, J.D. Explaining the cardiovascular risk associated with rheumatoid arthritis: Traditional risk factors versus markers of rheumatoid arthritis severity. Ann. Rheum. Dis. 2010, 69, 1920-1925. [CrossRef]

20. Solomon, D.H.; Greenberg, J.; Curtis, J.R.; Liu, M.; Farkouh, M.E.; Tsao, P.; Kremer, J.M.; Etzel, C.J. Derivation and internal validation of an expanded cardiovascular risk prediction score for rheumatoid arthritis: A Consortium of Rheumatology Researchers of North America Registry Study. Arthritis Rheumatol. 2015, 67, 1995-2003. [CrossRef]

21. Maradit-Kremers, H.; Crowson, C.S.; Nicola, P.J.; Ballman, K.V.; Roger, V.L.; Jacobsen, S.J.; Gabriel, S.E. Increased unrecognized coronary heart disease and sudden deaths in rheumatoid arthritis: A population-based cohort study. Arthritis Rheum. 2005, 52, 402-411. [CrossRef] [PubMed]

22. Maradit-Kremers, H.; Nicola, P.J.; Crowson, C.S.; Ballman, K.V.; Gabriel, S.E. Cardiovascular death in rheumatoid arthritis: A population-based study. Arthritis Rheum. 2005, 52, 722-732. [CrossRef] [PubMed]

23. Goodson, N.J.; Symmons, D.P.; Scott, D.G.; Bunn, D.; Lunt, M.; Silman, A.J. Baseline levels of C-reactive protein and prediction of death from cardiovascular disease in patients with inflammatory polyarthritis: A ten-year followup study of a primary care-based inception cohort. Arthritis Rheum. 2005, 52, 2293-2299. [CrossRef] [PubMed]

24. Meissner, Y.; Zink, A.; Kekow, J.; Rockwitz, K.; Liebhaber, A.; Zinke, S.; Gerhold, K.; Richter, A.; Listing, J.; Strangfeld, A. Impact of disease activity and treatment of comorbidities on the risk of myocardial infarction in rheumatoid arthritis. Arthritis Res. Ther. 2016, 18, 183. [CrossRef] [PubMed]

25. McMahon, M.; Grossman, J.; FitzGerald, J.; Dahlin-Lee, E.; Wallace, D.J.; Thong, B.Y.; Badsha, H.; Kalunian, K.; Charles, C.; Navab, M.; et al. Proinflammatory high-density lipoprotein as a biomarker for atherosclerosis in patients with systemic lupus erythematosus and rheumatoid arthritis. Arthritis Rheum. 2006, 54, 2541-2549. [CrossRef] [PubMed]

26. Navab, M.; Hama, S.Y.; Hough, G.P.; Subbanagounder, G.; Reddy, S.T.; Fogelman, A.M. A cell-free assay for detecting HDL that is dysfunctional in preventing the formation of or inactivating oxidized phospholipids. J. Lipid Res. 2001, 42, 1308-1317.

27. Navab, M.; Van Lenten, B.J.; Reddy, S.T.; Fogelman, A.M. High-density lipoprotein and the dynamics of atherosclerotic lesions. Circulation 2001, 104, 2386-2387. [CrossRef] 
28. Van Lenten, B.J.; Hama, S.Y.; de Beer, F.C.; Stafforini, D.M.; McIntyre, T.M.; Prescott, S.M.; La Du, B.N.; Fogelman, A.M.; Navab, M. Anti-inflammatory HDL becomes pro-inflammatory during the acute phase response. Loss of protective effect of HDL against LDL oxidation in aortic wall cell cocultures. J. Clin. Investig. 1995, 96, 2758-2767. [CrossRef]

29. Davis, J.M., 3rd; Maradit Kremers, H.; Crowson, C.S.; Nicola, P.J.; Ballman, K.V.; Therneau, T.M.; Roger, V.L.; Gabriel, S.E. Glucocorticoids and cardiovascular events in rheumatoid arthritis: A population-based cohort study. Arthritis Rheum. 2007, 56, 820-830. [CrossRef]

(C) 2019 by the authors. Licensee MDPI, Basel, Switzerland. This article is an open access article distributed under the terms and conditions of the Creative Commons Attribution (CC BY) license (http:/ / creativecommons.org/licenses/by/4.0/). 